|| ISSN(online): 2589-8698 || ISSN(print): 2589-868X ||

International Journal of Medical and Biomedical Studies

Available Online at www.ijmbs.info

NLM (National Library of Medicine ID: 101738825)

Index Copernicus Value 2018: 75.71

Volume 4, Issue 7; July: 2020; Page No. 24-27

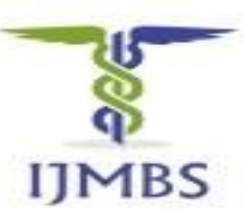

\title{
PAROTID HEMANGIOMA: CASE REPORT
}

Dr. Rohit Phadnis $\mathrm{K}^{\mathbf{1}}$, Dr. Chinamilli Jaahnavi ${ }^{2}$

${ }^{1}$ Assistant Professor, Department of General Surgery, AIMSR, Hyderabad

${ }^{2}$ Senior Resident, Department of General Surgery, AIMSR, Hyderabad

Article Info: Received 10 May 2020; Accepted 28 June 2020

DOI: https://doi.org/10.32553/ijmbs.v4i7.1267

Corresponding author: Dr. Chinamilli Jaahnavi

Conflict of interest: No conflict of interest.

\section{Abstract}

Backround: parotid hemangiomas are rare vascular benign tumors $0.4-0.6 \%$. Though capillary type of hemangiomas have been shown a good response to medical therary, cavernous hemangiomas usually require surgical excision.

Case report and discussion: 11 years girl with failure of medical treatment for parotid cavernous hemangioma was evaluated and operated with superficial conservative parotidectomy at aimsr, Hyderabad.

Review of literature: reports mostly tab propranolol to be treatment for the condition; it has guarded effect over cavernous hemangioma.

Conclusion: cavernous parotid hemangioma though rare, treatment mostly remains parotidectomy after proper evaluation for its feeding vessels.

\section{Introduction}

Hemangiomas are rare benign vascular tumors. They can occur anywhere in the body, but nearly $65 \%$ occur in the head and neck region of which $80 \%$ occur in the salivary glands. However these tumors account to only $0.4-0.6 \%$ of all parotid tumors. Capillary hemangiomas are known to occur in childhood, while adults are affected by cavernous type. We thus present this rare case of parotid cavernous hemangioma in a young girl that was managed surgically.

\section{CASE REPORT:}

A 11 year old female presented to the OPD with chief complaints of swelling in front of the left ear since 4 years. The swelling was gradually increasing in size, with discolouration of overlying skin. There was no pain upon mouth opening or chewing. The patient received treatment with tab. Propranolol 20mg twice daily for 6 months prior as prescribed by a pediatrician. However the swelling only reduced marginally in size. The patient presented to surgical OPD with concern for cosmesis.

Birth history was normal. There was no history of rash or skin lesions or swelling at birth. The child attained normal milestones and was immunized as per schedule. There was no significant family history.

On clinical examination a swelling of size $8 x 7 \mathrm{~cm}$ was present in the left parotid region. The swelling was soft, non tender, well defined and compressible. Local warmth was present. The overlying skin showed bluish discolouration. Bidigital and oral examination revealed there was no deep lobe involvement. Duct opening appeared normal

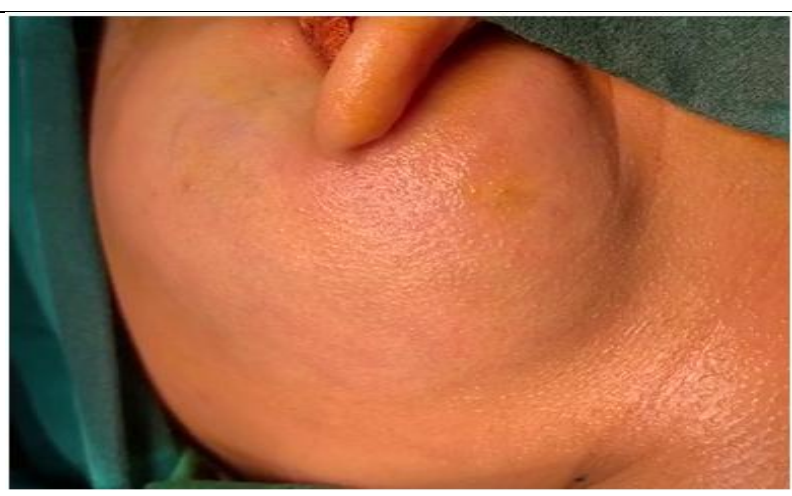

Figure 1: Preoperative picture showing swelling

Clinical diagnosis of hemangioma arising from the left parotid gland was made and confirmed by MRI of the head and neck. MRI T2Wt showed STIR hyper intense lesion measuring $6.4 \times 3.4 \times 7.2 \mathrm{~cm}$ that was involving both deep and superficial parotid lobes. The lesion was extending posteriorly upto the external auditory canal, posteromedially upto the upper part of the sternocleidomastoid, posteroinferiorly upto the pinna, superiorly upto the level of roof of EAC. Anterioly the swelling was free from the masseter and planes were well maintained. No intramuscular extension was noted. Carotid and parapharyngeal spaces remained free. The swelling appeared to be fed by branch of left external carotid artery and draining into the corresponding vein. There was a tiny speck of calcification noted within the swelling. Findings with respect to feeding vessels were confirmed by an MR angiogram. 


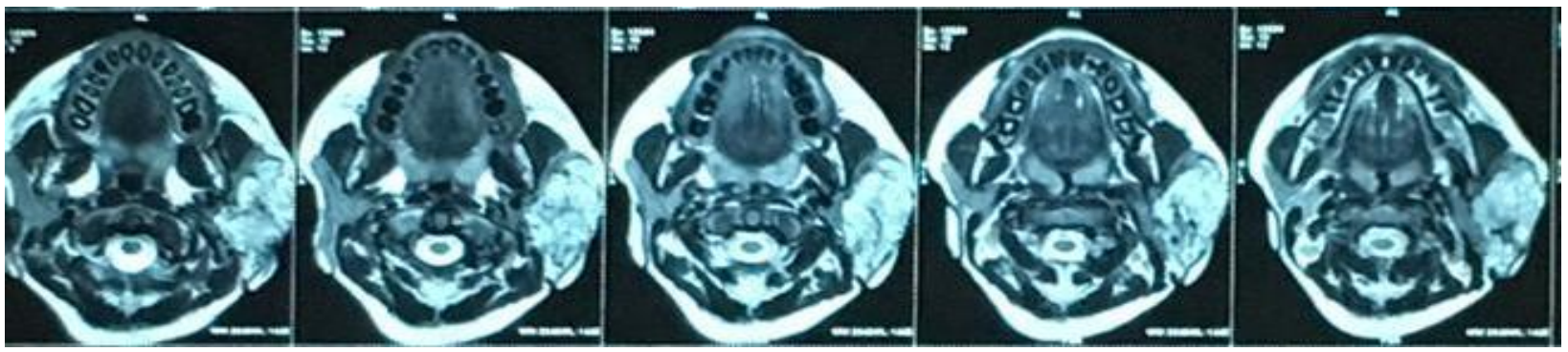

Figure 2: MRI head showing mass lesion arising from the left parotid gland

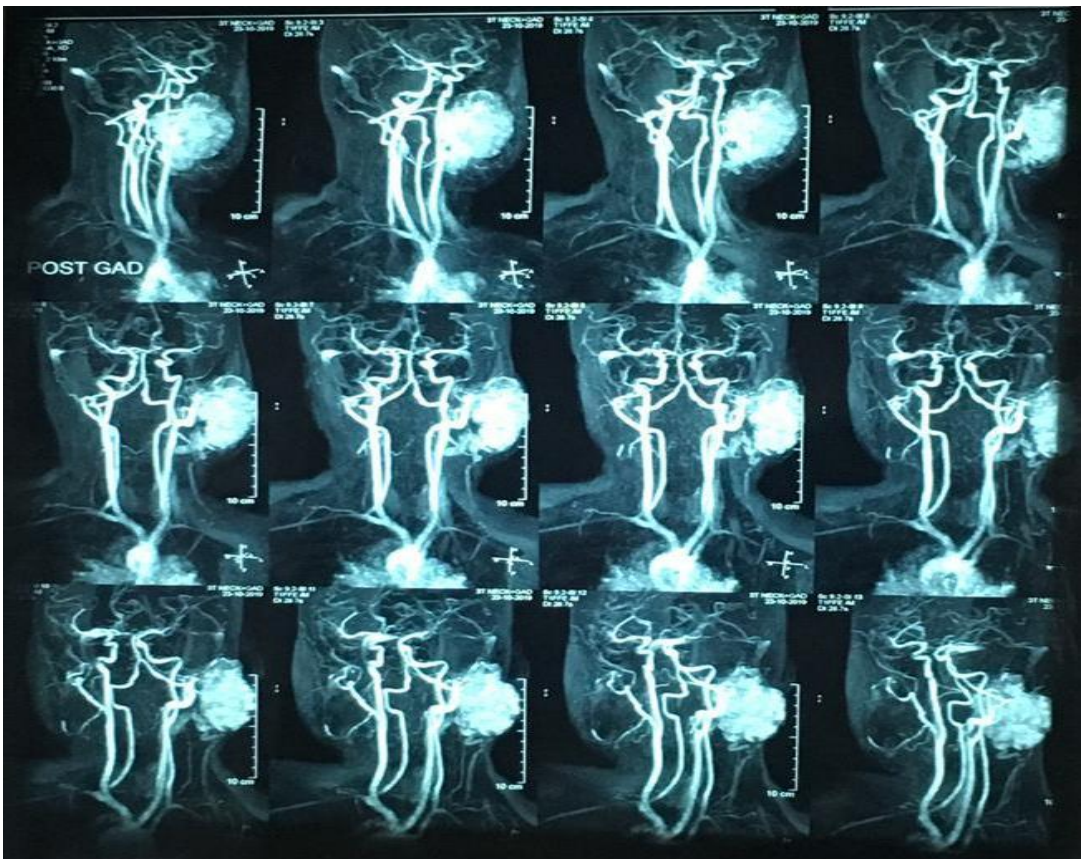

Figure 3: MR Angiogram

Routine preoperative investigations were done and adequate units of blood were reserved. Superficial parotidectomy was performed. Modified blairs incision was used. The facial nerve trunk was identified and dissection done from postero lateral aspect onwards. Several feeding vessels were identified arising from the posterior auricular artery, facial artery and the superficial temporal artery. All the feeding vessels were ligated, all grossly involved tissue has been dissected from in between

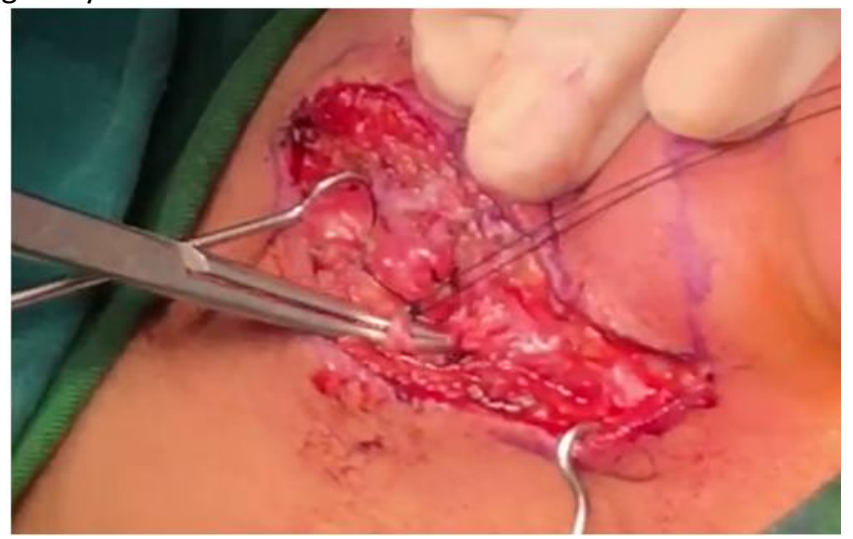

the branches of the facial nerve and superficial parotidectomy was done. Deep lobe was not ventured into as it appeared grossly uninvolved and for the risk of nerve injury in young patient. Redundant skin flap was excised and closure done over a suction drain. Care was taken not to displace the pinna. The specimen was sent for histopathology. Biopsy confirmed Cavernous hemangiomas arising within the parotid gland.

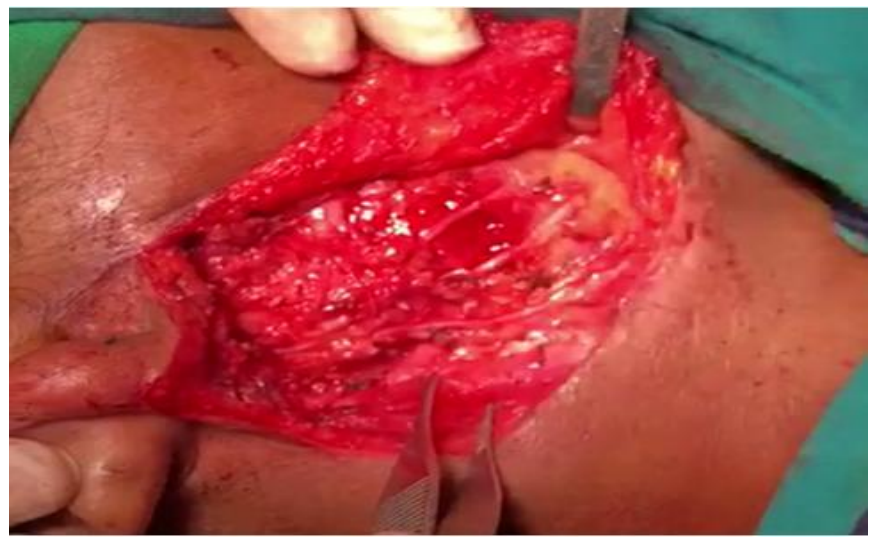

Fig 4a, 4b: Intraoperative pictures showing ligation of feeding vessels and intact facial nerve branches 
Postoperative recovery was uneventful. At follow up, there was no facial weakness, the hollow in the parotid region could no longer be seen and scarring was negligible.

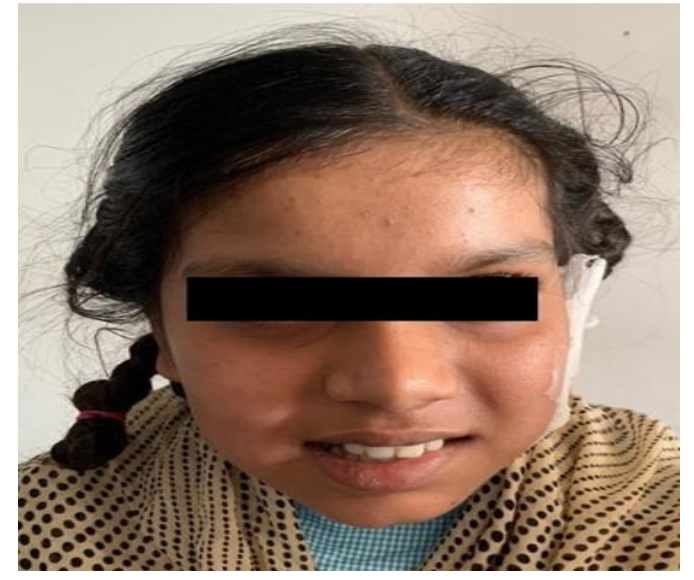

Figure 5: postoperative picture. There is no facial weakness and patient's smile is preserved

\section{Discussion}

Hemangiomas are rare benign vascular tumors characterized by increased proliferation of endothelial cells. They are commonly classified as capillary, cavernous, and mixed hemangiomas. Capillary hemangiomas are more common in infants, while most adult hemangiomas are cavernous type $^{(1)}$.

Hemangiomas can occur anywhere in the body but nearly $65 \%$ occur in the head and neck region. Of these $80 \%$ occur in the salivary glands, rest involving the skin and the muscles. Like most benign lesions of salivary glands, hemangiomas occur more commonly in the parotid gland, accounting to $0.4-0.6 \%$ of all parotid tumors ${ }^{(1)}$.

Parotid gland hemangiomas usually present within the first 3 decades of life, $>60 \%$ within the first year. Less than $2 \%$ cases present beyond the age of 40 years. These tumors are more common in females

The tumor usually presents as a soft, slow growing swelling in the region of parotid gland. Capillary hemangiomas of the skin remote from the area of parotid may be present at birth ${ }^{(1)}$. The overlying skin may rarely show red-bluish macula-papular lesions. Pain and trismus are rare features and usually indicate deep lobe involvement, acute thrombosis or hemorrhage within the tumor. However compression symptoms including those of the facial nerve are rare even in large tumors ${ }^{(2)}$.

Clinical examination findings include a compressible non tender swelling with a bruit. Turkey wattle sign was classically described as increase in size of swelling on lying down or leaning forwards. The sign is demonstrable in $>50 \%$ cases $^{(3)}$. Reddi's sign is a less known feature wherein the compression of the external and internal jugular veins causes the swelling to become more prominent due to obstruction to venous outflow ${ }^{(4)}$.

On ultrasound examination a homogenous hypoechoic lesion with internal septations is found and on Doppler large intratumoral vessels can be seen. On computaed tomography the tumor is seen as an intensly enhancing lesion within the parotid gland after giving IV contrast. MRI with angiogram is the most usefull investigation to delineate the feeding vessls. It is seen as a hypointense lesion on T1WT series and and hyperintense on T2WT series. There may be prominent flow voids, contrast enhancement ${ }^{(5)}$.

Red cell scintigraphy although the most accurate investigation, it is rarely used. It can be helpful in identifying any other hemangiomas in the body ${ }^{(5)}$.

\section{Management:}

Several modalities of treatment have been proven to be usefull in different studies and the choice of treatment is tailored to each patient. Infantile capillary hemangiomas are known to regress spontaneously after 2 years of age. Such cases may need only monitoring. For lesions that are persistent, drugs such as propranolol, interferon alpha2A therapy have been tried with variable rates of success ${ }^{(6)}$. Intralesional corticosteroids, sclerosant injections, cryotherapy, laser ablation are effective where expertise to identify and cannulate the feeding vessels is available ${ }^{(6)}$.

Cavernous hemangiomas on the other hand show little tendency towards regressing despite aggressive medical therapy $(1,6,7)$. Surgical resection in form of superficial or total parotidectomy, with ligation of feeding vessels is preferred line of treatment for cavernous hemangiomas of parotid gland. However there is a high probability of facial nerve injury especially in the setting of increased intraoperative bleeding. Preoperative selective embolisation can greatly help in reducing the tumor size as well as bleeding during surgery and needs to be considered in all cases ${ }^{(1,7)}$.

\section{Conclusion:}

Hemangiomas of the parotid gland, especially cavernous type in young children are extremely rare. Hemangiomas should be considered as a differential diagnosis in cases presenting with parotid swelling. Clinical diagnosis can be difficult but with appropriate imaging studies more cases may be diagnosed. While capillary hemangiomas in infants regress spontaneously or with medical management, cavernous hemangiomas will need definitive surgery.

\section{References}

1. Lara Sanchez H, Peral Cagigal B, Madrigal Rubiales B, VerrierHernandez A (2014) Cavernous Hemangioma Of The Parotid Gland In Adults. J Clin Exp Dent 6[5]: 592-594. 
2. Moses Nussbaum, Sergio Tan, Maxil Som (1977) Hemangioma Of The Salivary Glands: Five Salivary Hemangiomas Reports. New York.

3. Dempsey EF, Marley RS (1970) Vascular Malformations Simulating Salivary Gland Disease. Br J Plast Surg 23(1): 77-84

4. Reddi BR (2013) A Clinical Observation To Diagnose Parotid Hemangiomas, Indian J Surg 75(Suppl 1): 401-403.

5. Deepa Regina John Et Al., A Case Of Parotid Hemangiomas Of Infancy: Role Of Ultrasound And Doppler In The Diagnosis. Indian J Neonatal Medicine And Research, 2016. Jan, Vol-4(1): 10-12.
6. Hammoudi K, Moriniere SM, Lauvin A (2015) Unusual Parotid Swelling: What Is The Diagnosis? European Annal Of Otorhinolaryngology, Head And Neck Diseases 132: 165-166

7. Eugenia Popescu, Violeta Trandafir D, Negro N. Dobrin, Daniella Trandafi (2013) Hemangiomas Of The Parotid Gland: Case Report. Rev Med Chir Soc. Med Nat Laci 117(1): 227-232. 